\title{
Heartbeat: sex-related inequities versus differences in management and outcomes of patients with cardiovascular disease
}

doi:10.1136/heartjnl-2021-320350

Sex differences in clinical management and outcomes of patients with cardiovascular disease sometimes are due to healthcare inequities (which should be eliminated) but also might be due to sexrelated differences in aetiology and pathophysiology. For example, the optimal medical dose for management of heart failure with reduced ejection fraction (HFrEF) may be lower in women compared with men. In a study of 561 women and 615 men with a new diagnosis of either HRrEF or heart failure with preserved ejection fraction (HFpEF), Bots and colleagues ${ }^{1}$ found that although $79 \%$ of women and $86 \%$ of men with HFrEF were prescribed an ACE inhibitor (ACEI) or angiotensin receptor blocker (ARB), the average dose was only about $50 \%$ of the recommended target dose for both sexes. A lower ACEI/ARB dose was associated with higher survival outcomes in women, but not men, with HFrEF. In patients of both sexes with HFpEF, there was no relationship between medication dose and survival (figure 1).

In the accompanying editorial, Hassan and Ahmed ${ }^{2}$ comment that: 'Sex differences in HF outcomes may be further exacerbated by differences in medication pharmacokinetics and pharmacodynamics, with female-specific physiological factors including lower body mass, as well as decreased renal excretion and gastrointestinal enzymatic activity, leading to higher medication bioavailability. As a result, the administration of sex-neutral medication doses leads to greater drug exposure in female patients, which may subsequently lead to a higher incidence of adverse drug reactions. This raises the possibility of sexbased HF treatments to improve clinical outcomes. However, current guidelines adopt a 'one size fits all' approach, with an emphasis on target-dosed therapy. In this era of precision medicine, is it time to redefine optimal HF therapy based on the sex of the patient?'

Division of Cardiology, University of Washington, Seattle, Washington, USA

Correspondence to Professor Catherine M Otto, Division of Cardiology, University of Washington, Seattle, WA 98195, USA; cmotto@uw.edu

Catherine M Otto
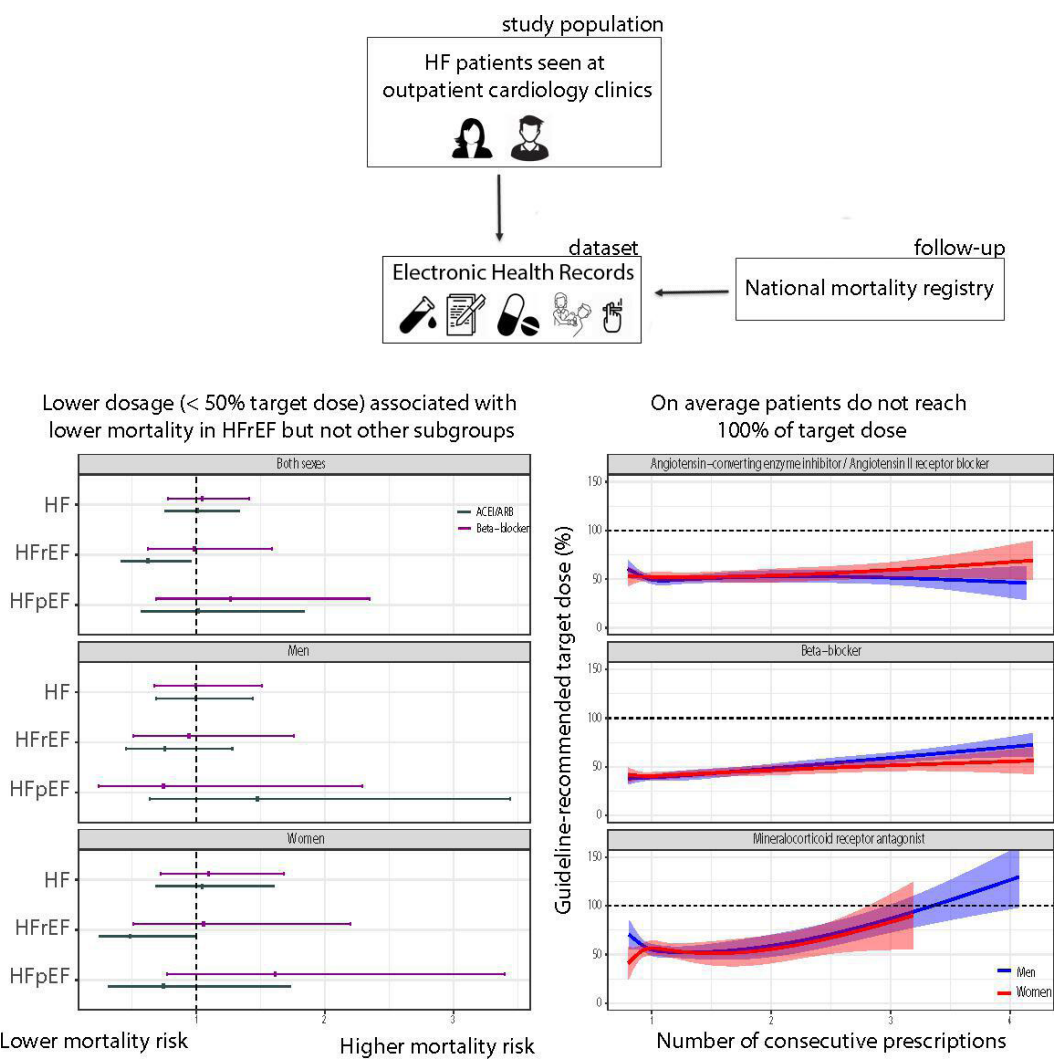

Figure 1 Central figure summarising the design and main findings of this study.

On the other hand, adverse outcomes in women with infective endocarditis likely are related to bias and healthcare inequities. In a multicentric Spanish cohort of 3541 patients $^{3}$ diagnosed with endocarditis between 2008 and 2018, women
Figure 2 Stratification of the GAMES ('Grupo de Apoyo al Manejo de la Endocarditis Infecciosa en España' or 'Spanish Collaboration on Endocarditis') cohort according to surgical recommendation between sexes. Overall and stratified mortality is displayed in each group. 


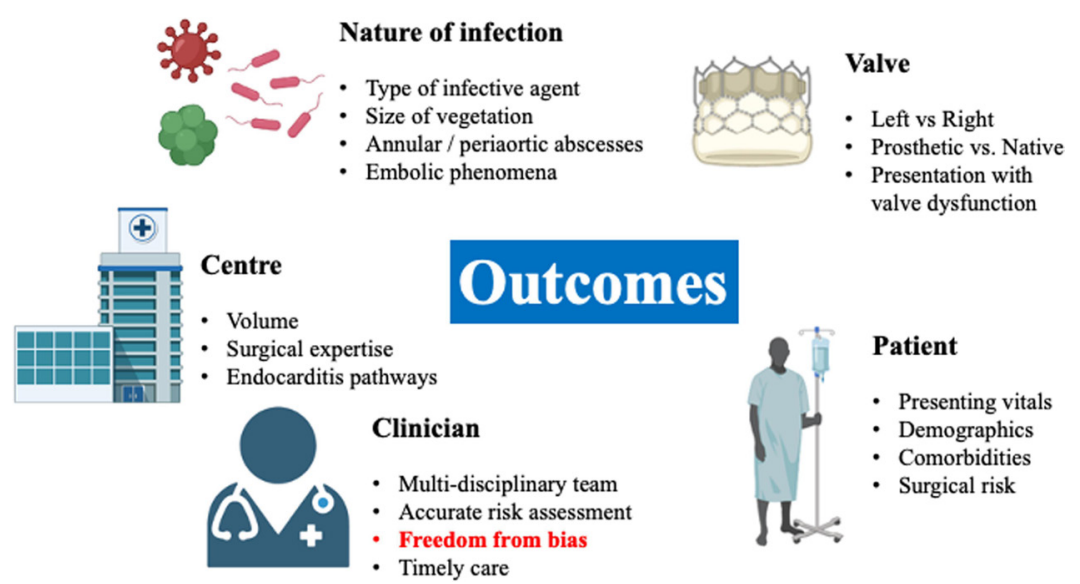

Figure 3 Factors associated with infective endocarditis outcomes.

persisted after propensity matching for age and surgical risk (OR 0.74; 95\% CI 0.59 to $0.91 ; p=0.05)$. In addition, women had a higher in-hospital mortality compared with men, even after adjusting for possible confounders (OR 1.41; 95\% CI 1.21 to $1.65 ; \mathrm{p}<0.001)$.

Van Spall, Jaffer and Mamas ${ }^{4}$ remind us of the many factors to be considered in the decision to recommend surgical intervention in a patient with endocarditis (figure 3). However, as they conclude: 'Disparities in referral and receipt of surgical intervention, along with differences in aetiology, microbiology and comorbidities, may be responsible for the higher risk of mortality in women than in men with IE. Ultimately, awareness of these issues should prompt a self-evaluation of biases on the part of clinicians such that objective, timely surgical referrals are made and interventions are offered regardless of demographic group. While the biology is not modifiable, the biases and care disparities are.'

Another interesting paper in this issue is the study by Sung and colleagues ${ }^{5}$ showing a positive, graded association between higher levels of physical activity and a higher prevalence, with more rapid progression, of coronary artery calcification (CAC). These findings were based on a cohort of 25485 Korean men and women with a median interval between CAC measurements of 3 years. In discussing these seeming paradoxical findings, Gulsin and Moss ${ }^{6}$ point out that although CAC is a surrogate marker for calcified atherosclerosis and is associated with a higher risk of myocardial infarction, treatment with a statin also accelerates deposition of calcified plaque, similar to the effects of physical activity in the current study. They also remind us that: (1) the severity of CAC at baseline is a key predictor of progression rates, (2) an increase in CAC score is not the same an accelerated rate of total atherosclerotic plaque progression, and (3) the risk of plaque rupture and clinical events is greatest within the necrotic core of noncalcified plaques. Thus, it is possible that an increase in CAC scores reflects a protective response and a transition to a more stable plaque morphology rather than more extensive atherosclerosis. They conclude: 'Sung and colleagues' have produced a timely manuscript that highlights the complexity of interpreting coronary artery calcium scores in patients who have implemented recommendations on physical activity or commenced on statin therapy. While proponents would argue that it is an effective tool to screen for subclinical atherosclerosis in asymptomatic individuals, clinicians should be cautious regarding the overuse of this test in otherwise healthy individuals. The coronary artery calcium paradox should not result in paradoxical care for our patients.'

The Education in Heart article ${ }^{7}$ in this issue provides an overview for clinicians to detect and manage mental issues in their patients with cardiovascular disease

Table 1 Key components of an image challenge question

\begin{tabular}{|c|c|c|c|}
\hline & Purpose & What to include & What to avoid \\
\hline Vignette & $\begin{array}{l}\text { Introduce the clinical } \\
\text { scenario. }\end{array}$ & $\begin{array}{l}\text { Up to } 200 \text { words with only the amount of information } \\
\text { required to answer the question. } \\
\text { Approximate age to protect patient privacy, for example, 'A } \\
\text { man in his } 60 \mathrm{~s}^{\prime} \text {. }\end{array}$ & $\begin{array}{l}\text { Patient characteristics such as race, disability or socioeconomic } \\
\text { status unless critical for the correct diagnosis. } \\
\text { Extraneous details in the history or physical examination. } \\
\text { Red herrings, or intentionally misleading information. }\end{array}$ \\
\hline Figure & $\begin{array}{l}\text { Show the relevant } \\
\text { finding. }\end{array}$ & $\begin{array}{l}\text { High-quality, still single image or multipanel figure, ideally } \\
\text { coloured. } \\
\text { Accompanying video for online version. } \\
\text { Very brief legend (eg, 'Transthoracic echocardiogram in the } \\
\text { parasternal-long axis orientation' or '12-lead ECG'). }\end{array}$ & $\begin{array}{l}\text { Identifying patient information (names, medical record numbers). } \\
\text { Interpretation of the image in the legend. }\end{array}$ \\
\hline Lead-in & Ask the question. & $\begin{array}{l}\text { A single clear question which allows the test-taker to answer } \\
\text { even before looking at the options. }\end{array}$ & $\begin{array}{l}\text { Negatively phrased lead-ins. } \\
\text { Questions which ask the reader to choose more than one correct } \\
\text { answer. } \\
\text { True/false questions (which sometimes masquerade as 'which of the } \\
\text { following statements are true'). }\end{array}$ \\
\hline $\begin{array}{l}\text { Answer } \\
\text { options }\end{array}$ & $\begin{array}{l}\text { Provide a set of } \\
\text { plausible answers to } \\
\text { the lead-in. }\end{array}$ & $\begin{array}{l}\text { Four or five short homogenous options. } \\
\text { Plausible distractors which need to be less correct than the } \\
\text { right answer. }\end{array}$ & $\begin{array}{l}\text { Explanations of 'why' in the answer options. } \\
\text { Long or complicated answer choices. } \\
\text { Ambiguous terms such as usually, often or useful. } \\
\text { Brand-name drugs or devices. }\end{array}$ \\
\hline
\end{tabular}


(CVD) . There is a reciprocal relationship between mental disorders and CVD: patients with mental disorders have a 1.5- to 3.0-fold higher risk of developing CVD and, conversely, the onset of CVD increases the risk of a developing a mental disorder by 2.2-fold.

The Cardiology in-Focus topic in this issue is a step-by-step guide to writing a Image Challenge question, authored by our Image Challenge Editor. ${ }^{8}$ We encourage both cardiology trainees and clinicians to submit Image Challenge questions to Heart, using this basic guide, because this type of question accelerates learning for both the author and the reader (table 1).

Funding The authors have not declared a specific grant for this research from any funding agency in the public, commercial or not-for-profit sectors.
Competing interests None declared.

Patient and public involvement Patients and/ or the public were not involved in the design, or conduct, or reporting, or dissemination plans of this research.

Patient consent for publication Not applicable.

Provenance and peer review Commissioned; internally peer reviewed.

(C) Author(s) (or their employer(s)) 2021. No commercial re-use. See rights and permissions. Published by BMJ.

\section{Check for updates}

To cite Otto CM. Heart 2021;107:1683-1685.

Heart 2021;107:1683-1685.

doi:10.1136/heartjnl-2021-320350

ORCID iD

Catherine M Otto http://orcid.org/0000-0002-05279392

\section{REFERENCES}

1 Bots SH, Onland-Moret NC, Tulevski II, et al. Heart failure medication dosage and survival in women and men seen at outpatient clinics. Heart 2021;107:1748-55.

2 Hassan R, Ahmed SB. Sex differences in heart failure and precision medicine: right patient, right time...wrong dose? Heart 2021;107:1692-3.

3 Varela Barca L, Vidal-Bonnet L, Fariñas MC, et al. Analysis of sex differences in the clinical presentation, management and prognosis of infective endocarditis in Spain. Heart 2021;107:1717-24.

4 Van Spall HGC, Jaffer I, Mamas MA. Bias: does it account for low surgical rates in women with infective endocarditis? Heart 2021;107:1688-9.

5 Sung K-C, Hong YS, Lee J-Y. Physical activity and the progression of coronary artery calcification. Heart 2021;107:1710-6.

6 Gulsin GS, Moss AJ. Coronary artery calcium paradox and physical activity. Heart 2021;107:1686-7.

7 Michal M, Beutel M. Mental disorders and cardiovascular disease: what should we be looking out for? Heart 2021;107:1756-61.

8 Krieger EV. How to write an image challenge multiple choice question. Heart 2021;107:1762-3. 